\title{
Erratum to: The Alzheimer's $\beta$-secretase BACE1 localizes to normal presynaptic terminals and to dystrophic presynaptic terminals surrounding amyloid plaques
}

\author{
Patty C. Kandalepas $\cdot$ Katherine R. Sadleir •
}

William A. Eimer · Jie Zhao $\cdot$ Daniel A. Nicholson •

Robert Vassar

Published online: 5 September 2013

(C) Springer-Verlag Berlin Heidelberg 2013

Erratum to: Acta Neuropathol (2013) 126:329-352

DOI 10.1007/s00401-013-1152-3

The authors regret that the following acknowledgment was not included in the original publication of the article:

We are especially indebted to the Cure Alzheimer's Fund (CAF) for funding a portion of this research (R.V.). Without the generosity of the CAF donors, this work could not have been completed.

The online version of the original article can be found under doi:10.1007/s00401-013-1152-3.

P. C. Kandalepas · K. R. Sadleir · W. A. Eimer · R. Vassar $(\bowtie)$ Department of Cell and Molecular Biology, The Feinberg School of Medicine, Northwestern University, 300 East Superior Street,

Tarry 8-713, Chicago, IL 60611-3006, USA

e-mail: r-vassar@northwestern.edu

J. Zhao

Department of Neuroscience, GlaxoSmithKline, Inc., 277 Niudun

Road, Pudong, Shanghai, China

D. A. Nicholson

Department of Neurological Sciences, Rush University Medical

Center, 1750 West Harrison Street, Jelke Building, Suite 1474,

Chicago, IL 60612, USA 